I raised the subject with The Chief Inspector of Prisons. She replied that .... prolonged treatment in prison is indeed an all too common way of managing psychotic prisoners.' She also reported that although arrangements to transfer prisoners from prison to hospita are better than they once were, there are still delays of months - much too long a time for a psychotic patient.

A prison is not designed to provide the level of expert care of a psychiatric hospital nor is it a community appropriate for the care of a person with chronic psychosis. How can we as a profession tolerate the present state of affairs?

Malcolm Faulk 23 St John's Street, Winchester, Hampshire SO23 OHF

\section{Assessment of capacity: a medico-legal challenge for decision makers}

Dr Jones, in her comprehensive article (Psychiatric Bulletin, November 2005, 29, 423-427), provides a review of the Mental Capacity Act 2005. The Act aims to provide a statutory framework to protect vulnerable people who may not be able to make their own decisions.

To ascertain current practice of local services as regards to assessment of capacity, we examined 60 randomly selected case notes of patients with learning disability in Lincoln (15 in-patients, 45 in the community; 42 males, mean age $=41$ years, s.d. $=13$, range 18-67).

Review of case notes revealed that patients needed to make a decision regarding their medication (36 patients), admission (15 patients), placement (6 patients), financial issues ( 2 patients) and a sexual relationship (1 patient). We found recorded evidence for assessment of capacity in 13 case notes (22\%). Clinicians had allocated more than one appointment in two-thirds of cases and used alternative and augmentative communications (sign language, Makaton and picture books) in 33 cases $(55 \%)$ to facilitate patients decision-making.

Our study also revealed the involvement of carers in a high proportion of cases $(45,75 \%)$ and reasonable consid eration for patients' wishes (24 cases, $40 \%$ ) but little evidence of involvement of advocates (3 cases, 5\%) and financial safeguard ( 2 cases, 3.3\%).

The assessment of capacity and detailed documentation required by the Mental Capacity Act 2005 will be a challenge for busy clinicians. Failure to implement safeguards for those who lack capacity will not only jeopardise the quality of care provided but will also infringe on patients' human rights and make decision makers vulnerable to lawsuits.

*Reza Kiani Senior House Officer in Psychiatry, Learning Disabilities Service, St George's Hospital,
Lincoln LN1 1FS, e-mail: reza.kiani@lpt.nhs.uk, Anayo Unachukwu Senior House Officer in Psychiatry, Enrique Bonell Consultant in sychiatry of Learning Disabilities, St George's Hospital, Lincoln

\section{Cholinesterase inhibitors and Alzheimer's disease}

Simpson et al (Psychiatric Bulletin, November 2005, 29, 410-412) state in their audit of the use of cholinesterase inhibitors that stopping these drugs in the latest stages of dementia 'is poor clinical practice and likely to have adverse outcomes'. They base this opinion on the fact that many of the patients in their sample deteriorated or died after their memory enhancers were discontinued when their Mini-Mental State Examination scores fell below 12 . The authors acknowledge that this high death rate could be because the patients who deteriorated or died were probably the most physically ill. In fact, this would be the simplest and most likely explanation. Therefore, the conclusion that stopping these drugs in the advanced stages of dementia constitutes poor clinical practice is really unfounded and could only be supported after the hypothesis is tested successfully in a controlled trial.

Rafael Euba Consultant and Senior Lecturer in Old Age Psychiatry, Memorial Hospital, Shooters Hill, London SE18 3RZ, e-mail: Rafael.Euba@oxleas. nhs.uk 